Sustainability, Agri, Food and Environmental Research, 2015, 3(1): 45-46

ISSN: 0719-3726

Carta al editor:

\title{
Situación actual del sector forestal
}

\section{Roberto Cornejo Espósito}

Presidente Nacional Colegio Ingenieros Forestales, San Isidro 22, oficina 503, Santiago de Chile, email: robertocornejoe@gmail.com

El sector Forestal tiene relevancia en la economía Nacional y Regional, siendo además el segundo rubro de mayor relevancia en las exportaciones después de la gran minería, teniendo el plus, que se basa en la explotación de recursos naturales renovables, asegurando su desarrollo sostenible y sustentable en el tiempo (Donoso \& Otero, 2005; INFOR, 2014). De igual modo esta actividad involucra fuertemente el tema social y ambiental, que pueda lograrse un desarrollo sustentable y adecuado a la realidad actual, efectivamente las grandes empresas han tomado con mayor responsabilidad tales temas, incorporando las certificaciones forestales, en las cuales deben de cumplir los aspectos sociales, ambientales como también el desarrollo sustentable y armónico con el medio ambiente CIFAG, 2015).

Actualmente se puede notar un cambio en estos temas, sin embargo, es un camino que se debe recorrer con gran energía, para que este cambio de hacer las cosas, sea tomado por todo el sector forestal y se pueda avanzar en los temas de desarrollo forestal con mayores criterios socio ambientales, que permitan un desarrollo integral de todos los actores, principalmente los pequeños propietarios, que no siempre han logrado los beneficios de este sector productivo (CIFAG, 2015).

Actualmente existen cerca de 2.000.000 hectáreas de suelos desarbolados y en su mayor parte degradados, los cuales presentan grandes procesos erosivos, que se encuentran en manos de los pequeños y medianos propietarios, son estas superficies las que deben recibir una repuesta real (INFOR, 2014; CIFAG, 2015). Consideramos que son estos suelos, en que el estado debe apoyar en forma más decidida, lo que implicaría definir a que sectores se pueden cultivar especies de rápido crecimiento, teniendo las consideraciones ambientales, como quebradas, cursos de agua y otros, además de tener presente que en sectores que es posible incorporar bosque nativo con adecuado resultado, promover actividades y proyectos de mayor incentivo, como el caso de forestaciones con quillay en que pueda desarrollarse con proyectos apícolas y extracción de saponina (como ejemplo)(INFOR, 2014).

El lograr incorporar que estos terrenos erosionados a la actividad forestal, permite por una parte disminuir la erosión de los suelos, como también darle una posibilidad de desarrollo a los pequeños propietarios y tener una mayor disponibilidad de biomasa y productos asociados, lo que da la posibilidad de ofrecer a las pequeñas y medianas empresas forestales materia prima 
Sustainability, Agri, Food and Environmental Research, 2015, 3(1): 45-46 ISSN: 0719-3726

disponible para sus actividades productivas. En este proceso estimamos imprescindible contar con el apoyo del estado, tanto para la formación del recurso, como también en el manejo de sus bosques, de manera que puedan obtener un adecuado desarrollo y logren la mayor producción de su recurso (Donoso \& Otero,2005). Dentro de este contexto, se podría concluir que es necesario apoyar a los pequeños productores con el fin de maximizar su productividad, lo cual implicaría ganancias económicas y sociales (CIFAG, 2015).

\section{Referencias}

Donoso, P.J. \& L.A. Otero, 2005. Hacia una definición de país forestal: ¿Dónde se sitúa Chile?. Bosque 26: 5-18.

Instituto Forestal- INFOR, 2014. Anuario Forestal. Boletín Estadístico 144. Santiago de Chile. $166 \mathrm{p}$.

Colegio de Ingenieros Forestales, Asociación Gremial - CIFAG, 2015. http://www.cifag.cl/_file/file_161_revista_mundo_forestal_28.pdf (visitado el 07 de febrero de 2015). 